\title{
Annalisa Bottacin, Prosper Mérimée - Vincenzo Salvagnoli. Carteggio inedito (1859-1860)
}

\section{Valentina Ponzetto}

\section{(2) OpenEdition}

1 Journals

\section{Edizione digitale}

URL: http://journals.openedition.org/studifrancesi/5673

DOI: $10.4000 /$ studifrancesi. 5673

ISSN: 2421-5856

\section{Editore}

Rosenberg \& Sellier

\section{Edizione cartacea}

Data di pubblicazione: 1 septembre 2011

Paginazione: 430-431

ISSN: 0039-2944

\section{Notizia bibliografica digitale}

Valentina Ponzetto, «Annalisa Bottacin, Prosper Mérimée - Vincenzo Salvagnoli. Carteggio inedito

(1859-1860)», Studi Francesi [Online], 164 (LV | II) | 2011, online dal 30 novembre 2015, consultato il 10 janvier 2021. URL: http://journals.openedition.org/studifrancesi/5673 ; DOI: https://doi.org/10.4000/ studifrancesi.5673

Questo documento è stato generato automaticamente il 10 janvier 2021.

\section{(c) 9 (i) $\Theta$}

Studi Francesi è distribuita con Licenza Creative Commons Attribuzione - Non commerciale - Non opere derivate 4.0 Internazionale. 


\title{
Annalisa Bottacin, Prosper Mérimée - Vincenzo Salvagnoli. Carteggio inedito (1859-1860)
}

\author{
Valentina Ponzetto
}

\section{NOTIZIA}

ANNALISA BotTACIN, Prosper Mérimée - Vincenzo Salvagnoli. Carteggio inedito (1859-1860), «Studi comparatistici», n³, anno II, fascicolo I, gennaio-giugno 2009, pp. 129-175.

1 Annalisa Bottacin, non nuova a questo genere di trouvailles, presenta in questo articolo un carteggio inedito fra Prosper Mérimée e Vincenzo Salvagnoli (1802-1861), avvocato liberale e uomo politico strettamente coinvolto nelle vicende del Risorgimento italiano, autore del discorso Della Indipendenza dell'Italia, Ministro degli Affari Ecclesiastici per il governo Ricasoli, poi senatore dal 1860.

2 Il carteggio si compone di tre autografi, due lettere di Mérimée a Salvagnoli del 24 settembre 1859 e 17 dicembre 1860 e una minuta di lettera di Salvagnoli a Mérimée del 7 dicembre 1860, conservate nell'archivio privato della famiglia Salvagnoli Marchetti ad Empoli, il cui contenuto è tutt'ora in corso di pubblicazione. Si tratta degli unici tre autografi sopravvissuti di un fitto scambio epistolare fra i due, durato verosimilmente dal 1842 al 1861, ma irrimediabilmente disperso nello sparpagliamento delle carte salvagnoliane. Le due lettere di Mérimée, la prima relativa al suo desiderio di ottenere un vescovado o canonicato in toscana, la seconda sulla situazione politica italiana, sono presentate sotto forma di riproduzione anastatica (pp.157-163), seguita da una trascrizione diplomatica ampiamente annotata che include anche la minuta del Salvagnoli (pp. 167-175).

Per introdurre e contestualizzare le lettere, una premessa sotto forma di breve saggio presenta la figura, il ruolo e il pensiero di Salvagnoli, evidenziando in particolare il suo rapporto con la Francia e ripercorrendo la storia della sua amicizia con Mérimée, ma 
anche con Stendhal, attraverso il quale i due si erano conosciuti nel 1842, e con il patriota emiliano Antonio Panizzi, interlocutore prediletto di Mérimée per quanto riguarda Salvagnoli. 